\title{
Effectiveness of Psycho-Physiological Portable Devices to Analyse Effect of Ergogenic Aids in Military Population
}

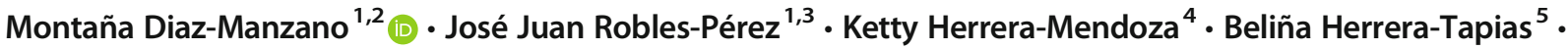 \\ Jesús Fernández-Lucas ${ }^{6,7}$. Susana Aznar-Lain ${ }^{8}$ • Vicente Javier Clemente-Suárez ${ }^{1,2,4,9}$
}

Received: 28 November 2017 / Accepted: 18 March 2018

(C) Springer Science+Business Media, LLC, part of Springer Nature 2018

\begin{abstract}
Caffeine is one of the ergogenic substances most used by warfighters in current operation areas, but the effect on the organic response and operational performed is already poor knowledge. This research aimed to study the acute effect of $400 \mathrm{mg}$ of caffeine monohydrate on the psycho-physiological response and rifle marksmanship of warfighters during a close quarter combat simulation. We analysed parameter of heart rate, blood lactate, cortical arousal, state anxiety and marksmanship of 20 Spanish Army veteran warfighters before and after a close quarter combat simulation in a double-blind procedure, also a correlation analysis was conducted between all the study variables. Marksmanship of warfighters did not improve with the caffeine ingestion, but it produced an increase in blood lactate concentration (caffeine: $1.9 \pm 0.5$ vs. $9.2 \pm 1.1$ mmol. ${ }^{-1}$; placebo: $1.8 \pm$ 0.7 vs. $6.9 \pm 2.2 \mathrm{mmol}^{-1} \mathrm{l}^{-1}$ ), cortical arousal (\% of change: caffeine: 2.51 ; placebo: -1.96 ) and heart rate (caffeine: $80.0 \pm 7.2$ vs. $172.9 \pm 28.2 \mathrm{bpm}$; placebo: $79.3 \pm 6.4$ vs. $154.0 \pm 26.8 \mathrm{bpm}$ ). In addition, higher heart rate values correlated negatively with marksmanship in close quarter combat. We concluded that caffeine intake did not improve the warfighters rifle marksmanship in close quarter combat possibly due to the increase in the physiological response.
\end{abstract}

Keywords Cortical arousal $\cdot$ Stress $\cdot$ Military $\cdot$ Heart rate $\cdot$ Lactate $\cdot$ Anxiety

This article is part of the Topical Collection on Education \& Training

Vicente Javier Clemente-Suárez

vctxente@yahoo.es

1 Studies Centre in Applied Combat (CESCA), Toledo, Spain

2 Applied Psychophysiological Research Group, European University of Madrid, Madrid, Spain

3 Light Forces Head Quarter of the Spanish Army, Madrid, Spain

4 Grupo de Investigación en Cultura, Educación y Sociedad, Universidad de la Costa, Barranquilla, Colombia

5 Grupo de Investigación en Derecho, Política y Sociedad, Universidad de la Costa, Barranquilla, Colombia

6 Applied Biotechnology Group, European University of Madrid, Madrid, Spain

7 Grupo de Investigación en Desarrollo Agroindustrial Sostenible, Universidad de la Costa, Barranquilla, Colombia

8 PAFS Research Group, Faculty of Sports Sciences, University of Castilla-La Mancha, Toledo, Spain

9 Faculty of Sport Sciences, Department of Sport Science, Calle Tajo, s/n, 28670 Villaviciosa de Odón, Madrid, Spain

\section{Introduction}

Warfare is one of the most stressful situations in which physiological and psychological demands are extreme, and the warfighter has to be in a constant state of alert, ready for any threat. This situation causes a decrease in the information processing and cortical arousal, founding in warfighters symptoms of central nervous system fatigue [1,2]. These negatively effects could affect the warfighters marksmanship and therefore their combat efficiency, and despite this state, the warfighter must maintain a high shooting efficiency to survive and complete the mission assigned [3]. Numerous ergogenic aids have been studied to help warfighters in combat, being caffeine one of the substances most studied, especially in sleep deprivation condition. Different authors reported after 100 to $400 \mathrm{mg}$ caffeine ingestion improvement in shooting targets in sleep deprivation conditions [4], reduction in target detection time [5], improved friend-foe discrimination on simulated sentry duty [6], improvement in sustain vigilance and psychomotor performance during military operation involving sleep deprivation [7], maintained physical performance [8], and improvement in target detection and engagement speed during a 
vigilance task [9]. In the other hand, other authors did not evaluate improvement in engagement speed [10] and marksmanship [5] after caffeine ingestion. This lack of improvement in marksmanship could be due to caffeine is an anxyogenic substance [10], but, nevertheless it is a substance widely used by warfighters.

It was demonstrated that caffeine intake improves the psychomotor levels of warfighters in fatigue conditions [4-6, 8]. It is also known that during combat, especially in urban combat and close quarter combat (CQC), levels of cortical arousal decrease $[1,2,11]$. Therefore, caffeine ingestion might improve cortical arousal level, increasing the information processing and improving the marksmanship of warfighters. A previous research specifically conducted in CQC with pistol guns in warfighters that took $400 \mathrm{mg}$ of caffeine, showed no improvement in marksmanship, possibly due to the hard control of pistol because the anxyogenic response after the caffeine ingestion [12]. Possibly the use of rifle gun could not be influenced by this negative anxyogenic effect in marksmanship since the control of the weapon is made by the two hands and the stock placed in the shoulder, increasing the stability in the shooting action. Many authors have studied the effect of different doses of caffeine in situations of sleep deprivation, but no one studied the effect of caffeine on stressful combat situation as CQC performed with the most used weapon in actual theater of operations, the rifle. Therefore, the present study aims to analyse the acute effect of a $400 \mathrm{mg}$ of caffeine monohydrate dose on psycho-physiological response and rifle marksmanship during a CQC simulation. The hypothesis of the present study was caffeine ingestion would increase marksmanship in CQC because caffeine would compensate the decrease in cortical arousal caused by the combat stress, and the rifle stock and grip would compensate the negative anxyogenic effect in the warfighter weapon control.

\section{Material \& Methods}

\section{Participants}

Twenty male warfighters of Spanish Army were recruited $(38.8 \pm 4.0$ years; $176.9 \pm 5.5 \mathrm{~cm} ; 79.8 \pm 8.6 \mathrm{~kg})$. They had $20.0 \pm 4.2$ years of professional experience in their units and experience in international missions in current conflicts. Warfighters were equipped with standard uniform, boots, tactical fighting load carrier, body armor and a HK G36-c (compact model) rifle. The characteristics of this rifle are: weight$2.82 \mathrm{~kg}$ (without magazine); length- $720 \mathrm{~mm}$ stock extended/ $500 \mathrm{~mm}$ stock folded; height- $278 \mathrm{~mm}$. Prior starting the research, the experimental procedures were explained to all the participants, who gave their voluntary written informed consent in accordance with the Declaration of Helsinki. The procedures conducted in the present research were designed and approved by the Medical Service of the Head Quarter of Spanish Light Forces and the Head Quarter of the Unit.

\section{Procedure}

We followed the procedure of a previous research $[12,13]$ to analyse effect of caffeine in CQC. We randomly divided the warfighters in 2 groups of 10 participants. Participants in the caffeine group ingested two pills containing $200 \mathrm{mg}$ of caffeine monohydrate and participants in the placebo group ingested two $200 \mathrm{mg}$ placebo pills (sucrose). Two days later we repeated the data collection, but placebo groups took caffeine pills and caffeine group took placebo pills. The dose of caffeine was $5.01 \mathrm{mg} \cdot \mathrm{kg}^{-1}$, the same dose as used in previous studies conducted with militaries $[10,12]$.

In both evaluation days, we conducted a basal sample of heart rate (HR), cortical arousal, state anxiety and blood lactate concentration, then caffeine of placebo pills were given to participants. After that, warfighters performed $30 \mathrm{~min}$ of rifle shooting exercises and then undertook a first task, (then the first task started after $30 \mathrm{~min}$ of placebo or caffeine ingestion). In this first task, they fired a G-36c rifle 5 times at a single target placed in front of the soldier at a distance of $7 \mathrm{~m}$ to test the rifle and calibrate it. After this, they shot five more times at a single target at a distance of $7 \mathrm{~m}$ and we measured both the score obtained and HR. We select the distance of $7 \mathrm{~m}$ because combat distances in CQC are short and during the CQC simulation all the shooting actions were at distances less than $7 \mathrm{~m}$. The scoring system was explained to warfighters before the start of the first task and was as follows: 10 point - principal vital area; 8 point - secondary vital area; 4 points rest of the body; 0 point - miss the target. The target and the different score areas are showed in Fig. 1.

Finished the first task, warfighters performed $10 \mathrm{~min}$ of aerobic exercise with the combat equip, running $1600 \mathrm{~m}$ on a track field (average speed: $2.7 \mathrm{~km} / \mathrm{h}$ ). After that ( $45 \mathrm{~min}$ after caffeine or placebo ingestion), they fired the rifle 5 times at a single target at a distance of $7 \mathrm{~m}$ (second task). The score obtained, and HR were measure. Then, they started the third task, the CQC simulation (70 min after caffeine or placebo ingestion). The time line of data collection is shown in Fig. 2. Each soldier had to cover a military obstacle track to simulate activation prior to combat and then they had to clear a trench in the minimum time, shooting all the targets that they found $[1,13]$. To complete this task soldier had only one magazine with 30 bullets. The movement of warfighters, the situation and distances of every target are showed in Fig. 3. Parameters of time of the maneuver, number and percentage of impact in 4 points area, number and percentage of impact in 8 points area, number and percentage of impact in 10 points area, total points, total shots, number of targets hit, total points/ total shots score ratio, (total points / total shots) / time ratio and total points/number of targets hit ratio were 


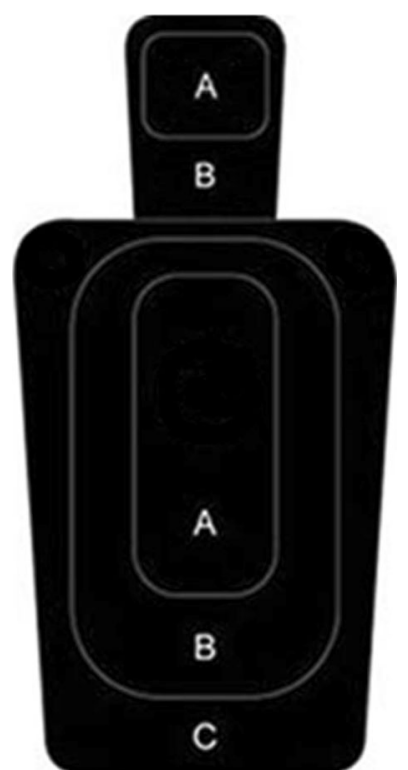

Fig. 1 Target and different scoring areas. A - principal vital area: 10 point; B - secondary vital area: 8 point; $\mathrm{C}$ - rest of the body: 4 points

measured. After finished the CQC simulation, blood lactate concentration, cortical arousal and state anxiety were evaluated. In the second evaluation day, warfighters shot the same number of target with the same distance to the target but in different position to avoid the learning effect.

The experimental procedure were performed at the installations of the Infantry Academy of the Spanish Army (Toledo, Spain), between 09:00 and 15:00, in temperatures between of $6.0{ }^{\circ} \mathrm{C}$ and $12.0{ }^{\circ} \mathrm{C}$, without rain, atmospheric pressure between of 966.5 and $963.2 \mathrm{mb}$ and with a wind velocity of 5.3$8.2 \mathrm{~km} / \mathrm{h}$. Warfighters performed the combats simulations with a minimum of $5 \mathrm{~h}$ of sleeping time prior to the activity, without eating or drinking for three hours prior to start the simulations, without take medication and without ingesting any product containing caffeine for two days before the study.

Cortical Activation was measured trough the Critical Flicker Fusion Threshold (CFFT) following the procedures conducted in previous studies $[12,14]$. An increase in CFFT suggests an increase in cortical arousal and information processing; by contrast, when values fall below the baseline, it suggests a reduction in the efficiency to process information and fatigue of central nervous system [15].

Blood lactate concentration was measured taking $5 \mu \mathrm{l}$ capillary blood of one finger and was analysed using a Lactate Pro analyser (Arkay, Inc., Kyoto, Japan). Increases in blood lactate concentration are relate with an increase in anaerobic metabolism. During shooting task, warfighters wore a HR transmitter belt (Polar Electro RS600, Kempele, Finland) to analyse $\mathrm{HR}$ and \%HRmax. HRmax was estimate using the formula proposed by Tanaka et al. [16]. An increase in HR suggests an increase in the organic response of subject.

State anxiety was evaluate using the CSAI-2R Spanish validated version [17], consisting of 17 items that assess cognitive anxiety (CA), somatic anxiety (SA) and self-confidence (SC), with five, seven and five items respectively. The response scale evaluated the intensity of each symptom on a scale of 1 (not at all) to 4 (very much). Higher scores on cognitive and somatic anxiety subscales indicated a higher level of anxiety, whereas higher scores on the selfconfidence subscale indicated a higher level of selfconfidence.

\section{Statistical Analysis}

The SPSS statistical package (version 17.0; SPSS, Inc., Chicago, Ill.) was used to analyse the data. Normality was test
Fig. 2 Time line of the data collection. CQC - Close Quarter Combat
10 TASK $30 \mathrm{~min}$ after caffeine

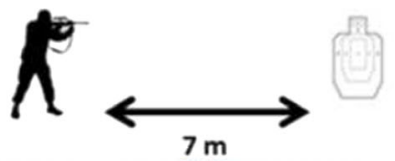

$7 \mathrm{~m}$

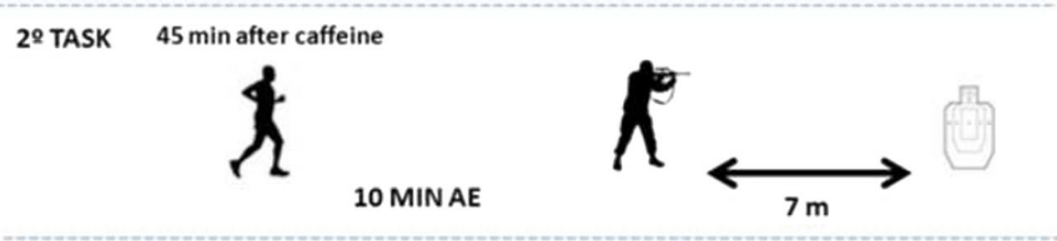

30 TASK 70 min after caffeine

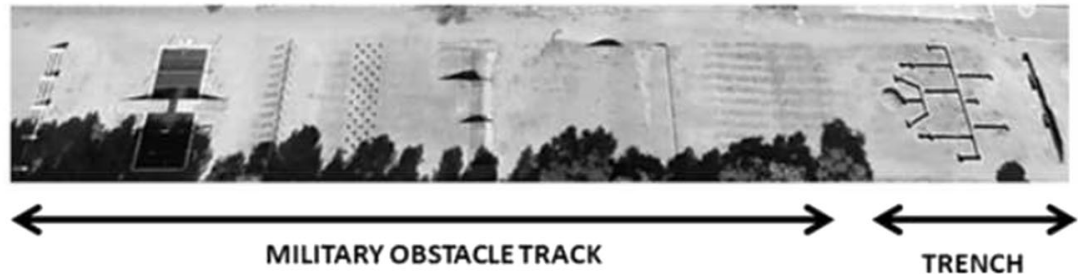


Fig. 3 Warfighters' movement, situation and distances of target in the trench $\left(3^{\circ}\right.$ task). Left figure First combat simulation; Right figure - Second combat simulation; Arrow - Start the chronometer; discontinuous line movements of soldier; continuous line - distance to target; body silhouettes- targets; five-point star - stop the chronometer


using the Shapiro-Wilks test. A one-way ANOVA test was used to compare the mean values between placebo and caffeine in the different tasks evaluated. A Friedman test was used to compare the mean values between shooting scores in the first and second shooting tasks in each situation. Bivariate correlation analysis between the psycho-physiological (cortical arousal, HR and lactate) and marksmanship parameter analysed in the third task were undertaken using a Pearson correlation analysis. The significance level was set at $p<0.05$.

\section{Results}

Basal HR was $73.4 \pm 2.3 \mathrm{bpm}, \mathrm{HR}, \% \mathrm{HRmax}$ and score in the first shooting task were similar for both caffeine and placebo ingestion. The \%HRmax in the $10 \mathrm{~min}$ of physical activity was significantly $(p<0.05)$ higher with the ingestion of caffeine than placebo (Table 1).

Time to clear the trench presented a tendency to reach higher values with the ingestion of caffeine. Values of $\%$ of impact in the principal vital area (10 points), the total point obtained, and total shots presented a tendency to reach higher values with placebo (Table 2).

The numbers of target reached were similar with the ingestion of both caffeine and placebo, but the total points/ total shots score ratio, (total points / total shots) / time ratio and total points/number of targets reached ratio presented a tendency to reach higher values with placebo (Table 3 ).
Values of HR, \%HRmax, lactate post and $\Delta$ CFFT presented significantly higher values with caffeine than with placebo ingestion (Table 4).

None of the parameter analysed in the CSAI-2R presented significantly differences (Table 5).

Correlation analysis showed a negative correlation between HR and the following parameter: total shots $(r=-.526$; $p=.036), 10$ points $(r=-.626 ; p=.009)$, total points $(r=$ $-.0546 ; p=.029)$, total points / number of targets reached $(r=-.499 ; p=.049)$, total points / total shots $\mathrm{x}$ time $(r=$ $-.610 ; p=.012)$.

\section{Discussion}

The aim of the present research was to analyse the acute effect of $400 \mathrm{mg}$ caffeine monohydrate dose on the psychophysiological response and rifle marksmanship in a CQC simulation. The hypothesis of the study was not confirmed since caffeine ingestion did not improve rifle marksmanship of warfighters.

No differences in marksmanship were observed after the ingestion of placebo and caffeine in the first task. This might be due to the task characteristics, shooting in rest condition, without stress or threats, and because it was conducted $30 \mathrm{~min}$ after the caffeine intake and it is not enough time to reach the highest effect of caffeine in the organism [18]. However, in the aerobic activity and the second shooting task the physiological

Table 1 Heart rate and score reached on $7 \mathrm{~m}$ shooting task and $7 \mathrm{~m}$ shooting task after physical activity shooting tasks

\begin{tabular}{|c|c|c|c|c|c|c|c|c|}
\hline & \multicolumn{3}{|l|}{$7 \mathrm{~m}$} & \multicolumn{2}{|c|}{10 min Physical Activity } & \multicolumn{3}{|c|}{$7 \mathrm{~m}$ after 10 min Physical Activity } \\
\hline & HR (bpm) & $\%$ HRmax & Score (point) & HR (bpm) & $\%$ HRmax & HR (bpm) & $\%$ HRmax & Score (point) \\
\hline Caffeine & $80.0 \pm 7.2$ & $43.0 \pm 1.2$ & $38.5 \pm 11.5$ & $153.9 \pm 21.9$ & $85.3 \pm 11.7$ & $110.3 \pm 19.9$ & $61.1 \pm 9.9$ & $44.7 \pm 5.4$ \\
\hline Placebo & $79.3 \pm 6.4$ & $43.8 \pm 1.1$ & $37.3 \pm 7.9$ & $143.0 \pm 22.6$ & $78.6 \pm 12.1^{*}$ & $100.3 \pm 12.9$ & $55.1 \pm 6.8$ & $37.7 \pm 15.7$ \\
\hline $\mathrm{F}$ & 2.045 & 2.418 & 2.093 & 2.045 & 2.418 & 1.981 & 2.460 & 2.552 \\
\hline $\mathrm{p}$ & .172 & .140 & .167 & .172 & .014 & .178 & .136 & .102 \\
\hline
\end{tabular}

$* \mathrm{p}<0.05$ placebo vs. Caffeine; $7 \mathrm{~m}$ - shoot a target at a distance of $7 \mathrm{~m} ; \mathrm{HR}-$ Heart Rate; $\% \mathrm{HR}$ - Percentage of Maximum Heart Rate. F and $p$ values obtained in the ANOVA analysis of Caffeine vs. placebo results 
Table 2 Time, total shots and distribution of points obtained on the trench task

\begin{tabular}{lllllllll}
\hline & Time (s) & 4 Points (n) & $\% 4$ points & 8 Points (n) & \% 8 points & 10 points (n) & $\% 10$ points & Total points \\
\hline Caffeine & $39.8 \pm 10.4$ & $3.0 \pm 2.1$ & $38.2 \pm 31.4$ & $2.9 \pm 1.9$ & $36.6 \pm 27.2$ & $2.6 \pm 3.7$ & $25.1 \pm 24.1$ & $61.3 \pm 42.8$ \\
Placebo & $37.2 \pm 9.3$ & $2.9 \pm 1.8$ & $30.5 \pm 16.9$ & $3.1 \pm 1.7$ & $33.4 \pm 15.4$ & $3.5 \pm 2.2$ & $36.0 \pm 15.9$ & $71.3 \pm 28.1$ \\
F & .190 & .415 & .168 & .018 & .612 & .162 & .096 & .253 \\
p & .669 & .529 & .688 & .896 & .447 & .693 & .762 & .622 \\
\hline
\end{tabular}

$\mathrm{n}$ - number. $\mathrm{F}$ and $\mathrm{p}$ values obtained in the ANOVA analysis of Caffeine vs. placebo results

Table 3 Shooting scores obtained on the trench task

\begin{tabular}{llllll}
\hline & Total Shots $(\mathrm{n})$ & $\mathrm{N}^{\circ}$ targets reached $(\mathrm{n})$ & Total points / Total shots & TPTS / Time & Total points/ $\mathrm{n}$ targets reached \\
\hline Caffeine & $8.5 \pm 4.6$ & $4.8 \pm 0.5$ & $7.0 \pm 1.6$ & $0.18 \pm 0.10$ & $12.7 \pm 8.4$ \\
Placebo & $9.5 \pm 3.4$ & $4.6 \pm 0.7$ & $7.4 \pm 0.9$ & $0.20 \pm 0.10$ & $15.3 \pm 5.8$ \\
$\mathrm{~F}$ & .431 & .000 & .000 & .243 & .371 \\
$\mathrm{p}$ & .521 & 1.000 & .999 & .629 & .551 \\
\hline
\end{tabular}

$\mathrm{n}$ - number; TPTS- Total points/Total shots; TPNT - Total points $/ \mathrm{N}^{\circ}$ targets reached

response with caffeine ingestion was higher (higher values of HR and \%HRmax) than with placebo ingestion. Even with higher HR, the score on the soothing task with caffeine was higher than with placebo intake. It could be explained because of the HR reached in this shooting task was not associated with a decrease in fine motor skill (110.3 $\pm 19.9 \mathrm{bpm})$ [19].

In the CQC simulation, the numbers of targets reached were similar with the ingestion of caffeine and placebo but analyzing more specific combat ratios related to combat survival, the differences between placebo and caffeine were higher. After placebo intake, warfighters reached higher values in the total points/total shots score ratio, (total points/total shots) / time ratio and in the total points/number of targets reached ratio than after caffeine intake. These results contrast with studies conducted in situations of sleep deprivation, in which caffeine administration appears to increase the marksmanship of warfighters [5] and the time of shooting targets [4], because caffeine counteracts the symptoms of fatigue caused by the sleep deprivation increasing cortical arousal [20]. However, in conditions without sleep deprivation as the CQC conducted in the present research, the increase in arousal levels caused by caffeine seems to do not increase the marksmanship of warfighters. This might be due to the large physiological activation produced by caffeine that caused a higher increase in lactate concentration and HR than placebo and these high HR values reached could deteriorate the warfighters fine motor skill [19]. This increase in cortical arousal found after the caffeine ingestion, that appears not very important for improving marksmanship, could be interesting to compensate the negative effect of combat stress and the decrease in cortical arousal on the reduction of operative memory in combat [21]. In this line, could be interesting to know the possible differences in the effect of this cortical activation substance in novel and veteran soldiers in combat, since in other

Table 4 Heart rate, blood lactate concentration and cortical arousal (Critical Flicker Fusion Threshold) results obtained on the trench task. F and $\mathrm{p}$ values obtained in the ANOVA analysis of Caffeine vs. placebo results

\begin{tabular}{lllllllll}
\hline & HR $(\mathrm{bpm})$ & $\%$ HRmax & $\begin{array}{l}\text { Lactate pre } \\
\left(\mathrm{mmol} .^{-1}\right)\end{array}$ & $\begin{array}{l}\text { Lactate post } \\
\left(\mathrm{mmol} . \mathrm{I}^{-1}\right)\end{array}$ & CFFT pre & CFFT post & $\begin{array}{l}\% \text { change } \\
\text { CFFT }\end{array}$ \\
\hline Caffeine & $172.9 \pm 28.2$ & $95.5 \pm 15.5$ & $1.9 \pm 0.5$ & $9.2 \pm 1.1 \%$ & $36.4 \pm 3.5$ & $37.3 \pm 2.9$ & 2.51 & $1.07 \pm 1.40$ \\
Placebo & $154.0 \pm 26.8^{*}$ & $84.9 \pm 15.2^{*}$ & $1.8 \pm 0.7$ & $6.9 \pm 2.2^{*}+$ & $36.3 \pm 1.5$ & $35.6 \pm 1.4$ & -1.96 & $-0.95 \pm 1.93^{*}$ \\
F & 1.772 & 1.646 & .103 & 1.458 & .011 & 1.930 & 1.690 & 1.529 \\
$\mathrm{p}$ & .204 & .022 & .942 & .033 & .916 & .185 & .210 & .023 \\
\hline
\end{tabular}

$\$ \mathrm{p}<0.05$ pre vs. post values; $* \mathrm{p}<0.05$ placebo vs. Caffeine; HR - Heart Rate; $\%$ HR - Percentage of Maximum Heart Rate; CFFT - Critical Flicker Fusion Threshold. $\mathrm{F}$ and $\mathrm{p}$ values obtained in the ANOVA analysis of Caffeine vs. placebo results 
Table 5 Pre and post close quarter combat state anxiety values

\begin{tabular}{lllllll}
\hline & CA pre & CA post & SA pre & SA post & SC pre & SC post \\
\hline Caffeine & $5.4 \pm 4.2$ & $7.0 \pm 5.6$ & $8.9 \pm 4.3$ & $9.7 \pm 5.7$ & $15.7 \pm 8.4$ & $13.9 \pm 3.2$ \\
Placebo & $5.1 \pm 4.6$ & $5.0 \pm 3.5$ & $6.6 \pm 3.6$ & $6.4 \pm 3.1$ & $16.4 \pm 3.0$ & $16.9 \pm 4.1$ \\
F & 1.122 & 1.424 & 2.752 & 2.498 & .110 & 1.047 \\
p & .304 & .250 & .134 & .134 & .744 & .321 \\
\hline
\end{tabular}

CA - cognitive anxiety; SA - somatic anxiety; SC - self-confidence. F and p values obtained in the ANOVA analysis of Caffeine vs. placebo results military activities experience modulated the psychophysiological response, having a direct effect on combat performance [22].

Analyzing parameters related with marksmanship, higher HR values negatively correlated with the lower marksmanship values during the CQC simulation. Therefore, caffeine ingestion would not be recommended in this situation due to the high physiological activation that increase HR causing a negative effect on marksmanship. The inverse correlation obtained between HR and marksmanship is opposite than the results obtained by archers [23, 24], which obtained the highest scores with different HR, not always with the lower HR as in this research. This fact might be due to the differences in the weapons, in the shooting situation, in the HR reached and the stress level. Another key factor as is the time to clear the trench, presented a tendency to reach higher values with the ingestion of caffeine. This fact cold be explained because warfighter in shooting action with higher heart rate take more time to conduct the shooting action [25], making them more vulnerable since they have more exposure time to be shoot till they shoot. In this line, others marksmanship parameters, as impact in principal vital area and total shots, presented a tendency to obtain lower values with the ingestion of caffeine, fact that also reinforce the no recommendation of caffeine in CQC because the negative effect of anxyogenic response caused by caffeine. In addition, the higher physiological response observed with the caffeine ingestion that in previous studies conducted with pistol [12] had a negative effect on marksmanship was also found with the rifle, showing how short and large weapons (with higher stability to shoot) are affected by the anxyogenic effect of caffeine.

After the CQC simulation, CA in caffeine group presented an increased tendency. The increased anxiety level has been document in previous studies in urban combat, and it was due to the elevated combat stress [11]. It appears that caffeine causes an increase in the anxiety response of warfighters during CQC, which might be due to the stimulating effect of caffeine in the central nervous system [20]. Another possible explanation could be that the higher somatic arousal caused by the caffeine intake was mis-interpreted by warfighters as higher anxiety [26] but the high SD of the data and the small number or subject analysed keep off the possibility of generalization these results, more studies with large number of subjects are required to clarify this fact.

\section{Practical Application}

Caffeine is one of the most common substances used by warfighters in the current operation areas. The caffeine intake could help warfighters in operations conducted in sleep deprivation condition as patrols and guards, but in stressful combat situations did not improve the shooting performance of warfighters, because the increased physiological activation caused by caffeine caused a negative effect in rifle marksmanship. In addition, the ingestion of caffeine seems to increase the anxyogenic response of warfighters, fact that could be dangerous in situation of friend-foe discrimination soothing action or operations conducted in presence of unarmed civilians, as in the current theater of operations. It would be interesting for future researches to study the effect of caffeine intake in prolonged urban combat or parachute operations where cortical arousal and information processing levels are highly affected by combat stress [11,27-37] and caffeine could be a useful aid to maintain the marksmanship of warfighters in sustained combat operations.

\section{Limitation of the Study}

The principal limitation of the study was the small number of warfighters analysed. The difficulty to found veteran soldier with experience in the actual theatres of operations limited the number of warfighters recruited to conduct the present research. In addition, the no control of caffeine blood level during the different tasks was a limitation to better understand of caffeine metabolism during the tasks.

\section{Conclusion}

The ingestion of $400 \mathrm{mg}$ of caffeine monohydrate did not improve rifle marksmanship in CQC. This dose produced an increase in cortical arousal, heart rate and lactate concentration of warfighters and a decreased tendency in rifle marksmanship. 


\section{Compliance with Ethical Standards}

Conflict of Interest None.

Ethical Approval All procedures performed in studies involving human participants were in accordance with the ethical standards of the institutional and/or national research committee and with the 1964 Helsinki declaration and its later amendments or comparable ethical standards.

Informed Consent Informed consent was obtained from all individual participants included in the study.

\section{References}

1. Clemente-Suárez, V., and Robles-Pérez, J., Organic response in a combat simulation. Sanid Mil. 68(2):97-100, 2012.

2. Clemente-Suárez, V., and Robles-Pérez, J., Psycho-physiological response in different combat situations. Editorial Académica Española: Saarbrücken, Deutschland, 2012.

3. Marine Corps, U. S., Combat stress. Washington: Departament of the Navy, 2000.

4. Tharion, W. J., Shukitt-Hale, B., and Lieberman, H., Caffeine effects on marksmanship during high-stress military training with 72 hour sleep deprivation. Aviat Space Environ Med. 74:309-314, 2003.

5. Johnson, R. F., and Merullo, D. J., Effects of caffeine and gender on vigilance and marksmanship. Proceedings of the Human Factors and Ergonomics Society. Santa Monica, CA: Human Factors and Ergonomics Society. 40(23):1217-1221, 1996.

6. Johnson RF, Merullo DJ. Friend-foe discrimination, caffeine, and sentry duty, Proceedings of the Human Factors \& Ergonomics Society 43rd Annual Meeting; Sep 27-Oct 1, Houston, TX. Santa Monica, CA: Human Factors and Ergonomics Society, 1999;1299303.

7. McLellan, T. M., Bell, D. G., and Kamimori, G. H., Caffeine improves physical performance during $24 \mathrm{~h}$ of active wakefulness. Aviat Space Environ Med. 75:666-672, 2004.

8. McLellan, T. M., Kamimori, G. H., Bell, D. G., Smith, I. F., Johnson, D., and Belenky, G., Caffeine maintains vigilance and marksmanship in simulated urban operations with sleep deprivation. Aviat Space Environ Med. 76:39-45, 2005.

9. Gillingham, R. L., Keefe, A. A., and Tikuisis, P., Acute caffeine intake before and after fatiguing exercise improves target shooting engagement time. Aviat Space Environ Med. 75(10):865-871, 2004.

10. Gillingham, R. L., Keefe, A. A., and Tikuisis, P., Effects of caffeine on target detection and rifle marksmanship. Ergonomics. 46(15): 1513-1530, 2003.

11. Clemente-Suárez, V., and Robles-Pérez, J., Psycho-physiological response of warfighters in urban combat. Ann Psychol. 29(2): 598-603, 2013. https://doi.org/10.1007/s10916-017-0749-9.

12. Clemente-Suarez, V. J., and Robles-Pérez, J. J., Acute effects of caffeine supplementation on cortical arousal, anxiety, physiological response and marksmanship in close quarter combat. Ergonomics. 58(11):1-9, 2015. https://doi.org/10.1080/00140139.2015. 1036790 .

13. Clemente-Suárez, V., and Mechanical, R.-P. J., Physical and physiological analysis of symmetrical and asymmetrical combat. J Strength Cond Res. 27(9):2420-2426, 2012. https://doi.org/10. 1519/JSC.0b013e31828055e9.

14. Clemente-Suárez, V. J., Robles-Pérez, J. J., and Montañez-Toledo, P., Respuesta psicofisiológica en un salto táctico paracaidista a gran altitud. A propósito de un caso. Arch Med Deporte. 32(3):144-148, 2015.

15. Saito S., Does fatigue exist in a quantitative measurement of eye movements? Ergonomics. 1992;35: 607-15, 5-6.

16. Tanaka, H., Monahan, K. D., and Seals, D. R., Age-predicted maximal heart rate revisited. J Am Col Cardiol. 37(1):153-156, 2001.

17. Andrade, E. M., Lois, G., and Arce, C., 2007. Psychometric properties of the Spanish version of the revised competitive state anxiety inventory-2 with athletes. Psicothema. 19(1):150-155, 2007.

18. Bell, D. G., Jacobs, I., McLellan, T. M., and Zamecnik, J., Reducing the dose of combined caffeine and ephedrine preserves the ergogenic effect. Aviat Space Environ Med. 71:415-419, 2000.

19. Grossman, D. C., On combat: The psychology and physiology of deadly conflict in war and in peace. Belleville, IL: PPCT Research Publications, 2004.

20. Lorist, M., and Tops, M., Caffeine, fatigue, and cognition. Brain Cogn 53(1):82-94, 2003.

21. Gallego P, Robles-Pérez JJ, Clemente Suárez VJ. Effect of combat stress in warfighter operative memory. Study case. $9^{\circ}$ National Congress of Defense Nursing. Madrid. 18/06/2014

22. Clemente-Suárez, V. J., de la Vega, R., Robles-Pérez, J. J., Lautenschlaeger, M., and Fernández-Lucas, J., Experience modulates the psychophysiological response of airborne warfighters during a tactical combat parachute jump. Int J Psychophysiol. 110: 212-216, 2016. https://doi.org/10.1016/j.jpsycho.2016.07.502.

23. Martínez, M., Breeze rate and heart rate of archer in shooting position. Apunts. 20:53-60, 1990.

24. Byung-Hyun, K., Dong-Sung, S., Byung-Ki, L., and Han-Kyu, L., The optimal arousal level of the archery performance. Korean. J Sport Sci. 1:41-50, 1989.

25. Nibbeling, N., Oudejans, R. R., Cañal-Bruland, R., van der Wurff, P., and Daanen, H. A., Pursue or shoot? Effects of exercise-induced fatigue on the transition from running to rifle shooting in a pursuit task. Ergonomics. 56(12):1877-1888, 2013.

26. Schachter, S., and Singer, J., Cognitive, social, and physiological determinants of emotional state. Psychol Rev. 69(5):379-399, 1962.

27. Clemente-Suárez, V., The application of cortical arousal assessment to control neuromuscular fatigue during strength training. J Mot Behav. 49(4):429-434, 2017. https://doi.org/10.1080/00222895. 2016.1241741.

28. Clemente-Suárez, V. J., Robles-Pérez, J. J., and Fernández-Lucas, J., Psycho-physiological response in an automatic parachute jump. J Sports Sci. 35(19):1872-1878, 2017. https://doi.org/10.1080/ 02640414.2016.1240878.

29. Tornero-Aguilera, J., Robles-Pérez, J. J., and Clemente-Suárez, V. J., Effect of combat stress in the psychophysiological response of elite and non-elite soldiers. J Med Syst. 41(6):100, 2017. https://doi. org/10.1007/s10916-017-0748-x.

30. Sánchez-Molina, J., Robles-Pérez, J. J., and Clemente-Suárez, V. J., Effect of parachute jump in the psychophysiological response of soldiers in urban combat. J Med Syst. 41(6):99, 2017. https://doi. org/10.1007/s10916-017-0749-9.

31. Delgado-Moreno, R., Robles-Pérez, J. J., and Clemente-Suárez, V. J., Combat stress decreases memory of warfighters in action. J Med Syst. 41(8):124, 2017. https://doi.org/10.1007/s10916-017-0772-x.

32. Clemente-Suárez, V. J., Delgado-Moreno, R., González-Gómez, B., and Robles-Pérez, J. J., Respuesta psicofisiológica en un salto táctico paracaidista HAHO: caso de Estudio. Sanidad Mil 71(3): 179-182, 2015.

33. Clemente-Suárez, V. J., Diaz-Manzano, M., and Robles-Pérez, J. J., Use of minicameras to improve operative procedure in security forces. J Med Syst. 41(9):130, 2017. https://doi.org/10.1007/ s10916-017-0779-3.

34. Clemente-Suárez, V. J., Robles-Pérez, J. J., and Fernández-Lucas, J., Psychophysiological response in parachute jumps, the effect of 
experience and type of jump. Physiol Behav 179:178-183, 2017. https://doi.org/10.1016/j.physbeh.2017.06.006.

35. Sánchez-Molina, J., Robles-Pérez, J. J., and Clemente-Suárez, V. J., Respuesta fisiológica de una unidad paracaidista en combate urbano. Arch Med Deporte 34(3):66-70, 2017.

36. Clemente-Suarez, V. J., Palomera, P. R., and Robles-Pérez, J. J., Psychophysiological response to acute-high-stress combat situations in professional soldiers. Stress Health, 2017. https://doi. org/10.1002/smi.2778.

37. Clemente-Suarez, V. J., Robles-Pérez, J. J., Herrera-Mendoza, K., Herrera-Tapias, B., and Fernández-Lucas, J., Psychophysiological response and fine motor skills in high-altitude parachute jumps. High Alt Med Biol 18(4):392-399, 2017. https://doi.org/10.1089/ ham.2017.0071. 